Journal Of Al-Azhar University Engineering Sector

VOL. 14, NO. 50, JANUARY, 2019, 121-128

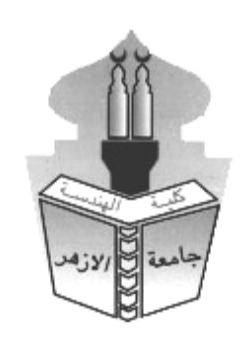

\title{
VOLTAGE SAG ENHANCEMENT IN MICROGRID WITH APPLICATIONS ON SENSITIVE LOADS
}

\author{
Montaserbillah Hafez ${ }^{1}$, Hussein El-Eissawi ${ }^{1}$ and Mohamed Al-Gazar ${ }^{2}$ \\ ${ }^{1}$ Egyptian Atomic Energy Authority, Nuclear Research Center, Cairo, Egypt \\ ${ }^{2}$ Electrical Engineering Department, Faculty of Engineering, AL-Azhar University, Egypt
}

\begin{abstract}
Although one of the main problems of the power quality is voltage sag in nuclear installations, the terminology used for the compensation devices is different. A Thyristor switched capacitor control is one of the equipment for voltage disturbance mitigation. This paper suggests a Thyristor Switched Capacitor control for mitigation of voltage sag in nuclear research reactor as a sensitive load. Performance of the proposed control investigated under different types of voltage sag magnitudes and is modeled using the user-defined dynamic modeling (UDM) tools in ETAP. The results show appropriate operation of the proposed control system to examine the developed technique.
\end{abstract}

\section{Keywords: Power Quality, Voltage Sag, Thyristor Switched Capacitor, ETAP}

\section{INTRODUCTION}

A microgrid has own resources to keep the power quality, mainly the frequency and voltage rated values. The variations of voltage depend on the system reactive power, while the frequency depends on the system active power balance [1].

Power quality is an important issue due to its impact on electricity suppliers, equipment manufactures and customers. The Power quality definition according to the IEEE Standard 1100 "The concept of powering and grounding electronic equipment in a manner suitable to the operation of that equipment and compatible with the premise wiring system and other connected equipment" [2]. Power quality disturbances include phenomena such as voltage sag, voltage swell, flicker, and harmonics distortion [3].

Voltage sag in the electric power system can happen more than any other power quality disturbances [4]. The voltage sag definition according to the IEEE Standard 1159, "The decrease in the root mean square (RMS) voltage level to $10 \%-90 \%$ of nominal value, at the power frequency for durations of half cycle to one minute" [5]. It is caused by large motors starting or by faults in the electric power system.

The use of Thyristor Switching Capacitors (TSC) is used to mitigation of voltage sag. This paper discusses the aspects of the thyristor switch capacitor control algorithm. Typical operating times of thyristor switching capacitor are in the range of a 5 milliseconds to one second and thus their interrelation with fast voltage sags which operate in the 10 millisecond to one minute [6][8]. 


\section{Thyristor Switched Capacitor Banks Controller}

To achieve the design objectives, the thyristor switched capacitor banks controller consisted of three different major components [9]- [12]:

PLC Controller: The operation of the PLC controller is described in figure 1 . The band center point shows the middle point of the regulation dead band. Since the operation of the switching capacitor is non-continuous, the switching action is stopped as long as the terminal bus voltage stays within the band defined by the lower and upper voltage limits [13], [14].

The PLC determines how many capacitor banks need to be switched in to compensate the voltage sag as close as possible to the center of the dead band. There is no switching action, when the voltage at the bus return to the band until the bus voltage goes above or below the upper and lower value limits.

In addition, the PLC controller sends signals to the initial operation timer and to the upper and lower voltage exceed timers. Once the initial timer reaches the pre-defined value, a second operational time delay is worked [15]

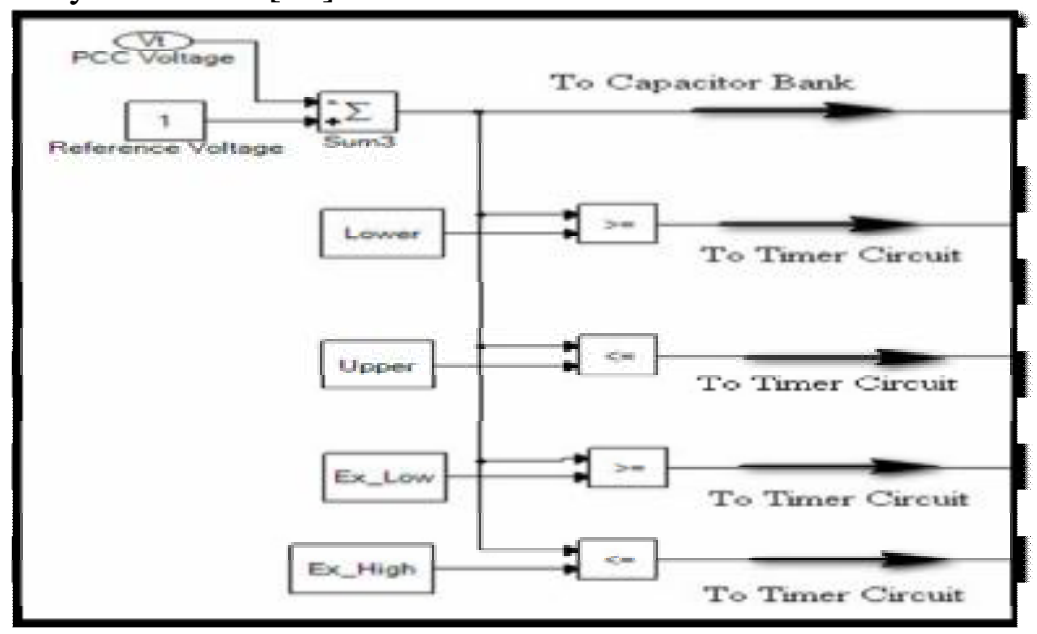

Figure 1: PLC Controller

The Timer Circuit: it consists of an automatic switch, gain, sum, time input and relational operator as shown in figure 2. This implementation is used to illustrate a timer for any other UDM model timer. The output of the timer circuit is directed to the operational time delay circuit. The switching capacitor action occurs after this additional time delay circuit has ended. Only a contactor operational time delay circuit is inserted before switching in or out the capacitor banks [16].

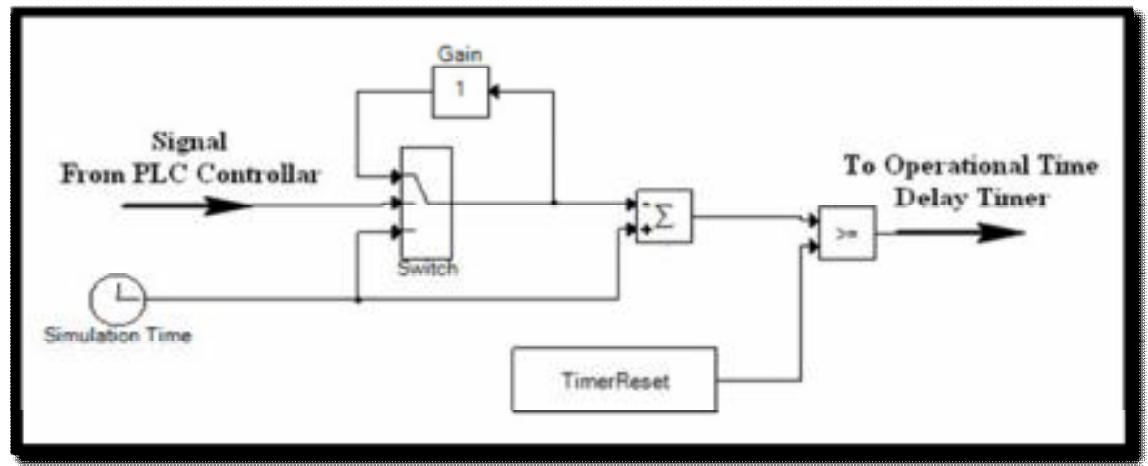

Figure 2: Timer circuit 
The controller transfer function has three timers, this timers and their application are inserted in table 1 . The timers are operated by the PLC, lower limits, and upper limits.

Table 1: Timers and its function

\begin{tabular}{|c|c|}
\hline Timer & Function \\
\hline Close switch & Add capacitor \\
\hline Open switch & Remove capacitor \\
\hline Operational Time Delay & $\begin{array}{c}\text { Working time to change } \\
\text { in or out the capacitor banks }\end{array}$ \\
\hline
\end{tabular}

The Capacitor Banks: they are designed as constant impedance devices once switched on. The number of capacitor banks required to raise the voltage is predetermined. For the implementation presented in this case, ten capacitor banks were used, each rated reactive power is 0.25 Mvar. The switching device time delay is designed along with the mathematical representation of the capacitance being added to the system. Figure 3 illustrations the function of constant impedance capacitor banks. The number and size of the capacitor banks are pre-determined based on the desired quantity of correction [17].

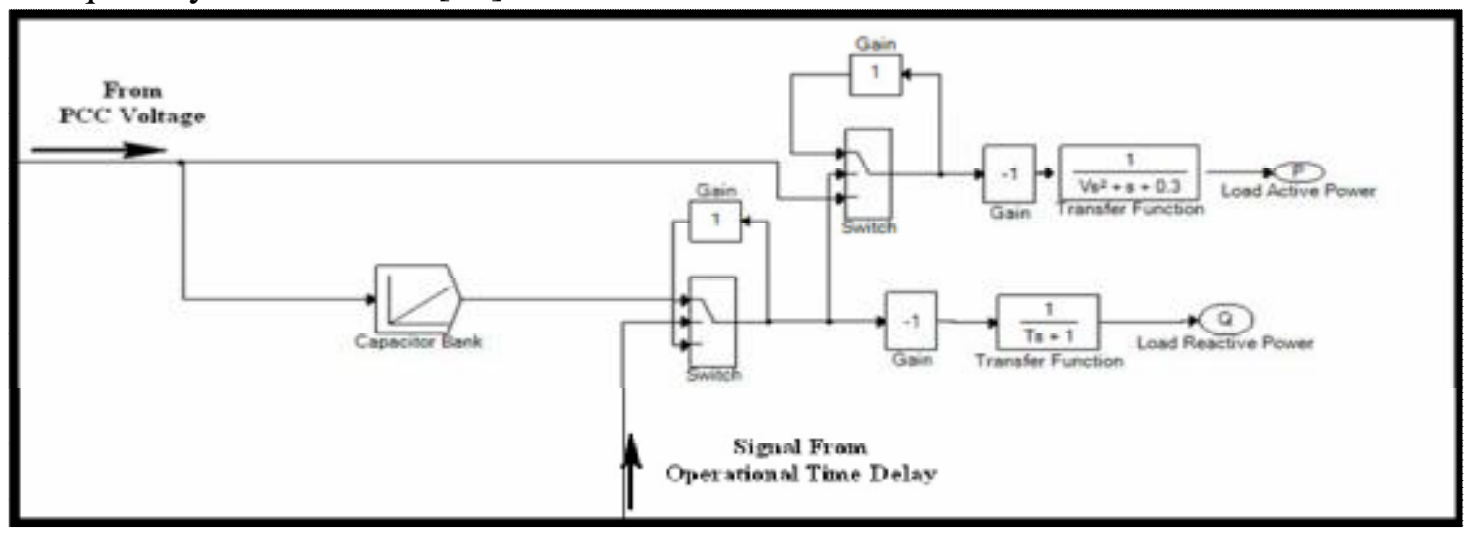

Figure 3: Definite Time Logic Implementation

The amount of banks capacitor is chosen based on the bus voltage to sense the voltage. After the timer retard, the capacitor banks are switched to adjust the reactive power. The desired voltage is adjusted to increase the general implementation of the system. If the bus voltage value exceeds the upper or lower thresholds, then the required numbers of capacitor banks are immediately switched in or out to avoid the system extreme conditions [18].

\section{SIMULATION USING ETAP}

In this paper, the application of thyristor switched capacitor bank in the nuclear research reactor is built in ETAP 12.6.0. A feeder with short-circuit power $S_{\mathrm{sc}}=65 \mathrm{MVAsc}$ connected to the $11 \mathrm{kV}$ bus, bus 2 which is Point of Common Coupling (PCC) connected to the $11 \mathrm{kV}$ bus via $500 \mathrm{kVA}(11 / 0.4 \mathrm{kV})$ transformer. There are four lumped loads 100KVA for each, two static loads and the other are motor loads. In addition, Lumped load 5 is an external load and connected in bus 6 . The one-line diagram is shown in figure 4 , and the relevant element parameters are shown in the diagram. 


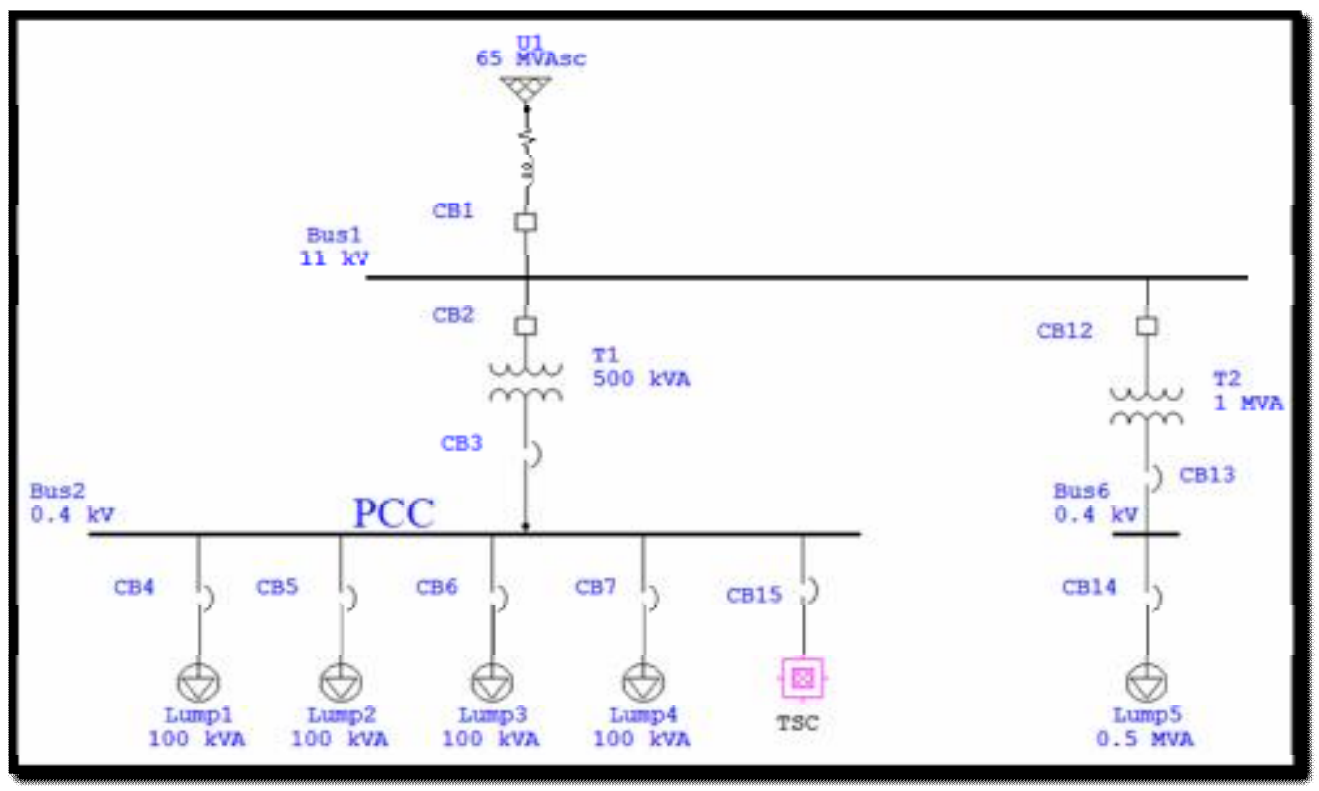

Figure 4: Circuit model in ETAP 12.6

When a three phase fault occurs in bus 6 for duration of $400 \mathrm{~ms}$, from $\mathrm{t}=100 \mathrm{~ms}$ till $\mathrm{t}=500 \mathrm{~ms}$, the PCC senses this fault as voltage sag. We can mitigate the voltage sag by using thyristor switched capacitor bank.

The proposed TSC is working automatically when the voltage is less than $0.9 \mathrm{pu}$. It injects reactive power according to the value of the voltage decreased. All the following figures will be divided into two plots (a) the PCC voltage without TSC, and (b) the PCC voltage with TSC.

The PCC voltage with sag $15 \%$ :

When The PCC voltage is decreased to $85.84 \%$ of its normal value, for duration $400 \mathrm{~ms}$, from $\mathrm{t}=$ $100 \mathrm{~ms}$ till $\mathrm{t}=500 \mathrm{~ms}$, as shown in figure (5-a). The TSC mitigates the PCC voltage to $94.65 \%$ with $\mathrm{Q}=0.848$ Mvar, as shown in figure (5-b).

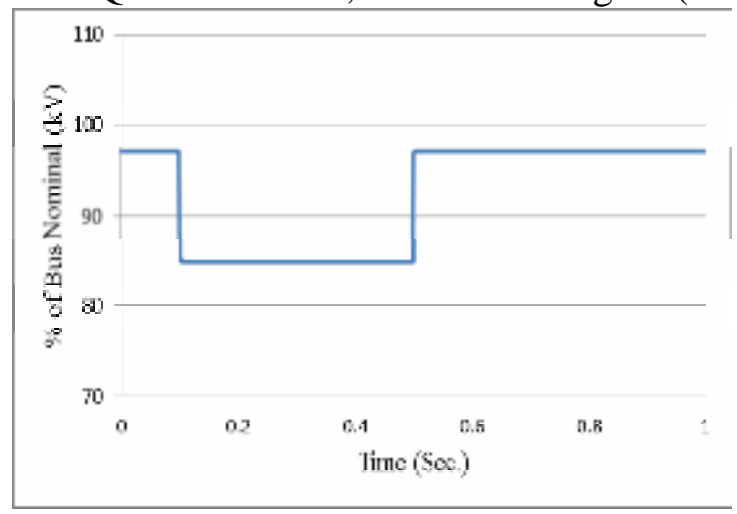

(a)

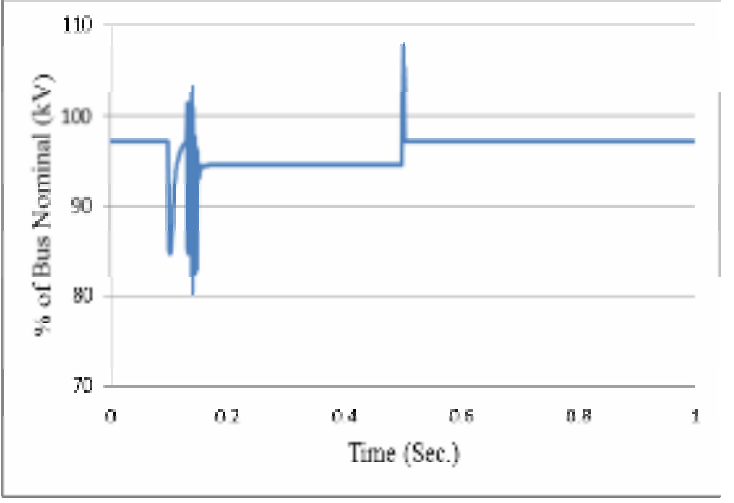

(b)

Figure 5: The PCC voltage with sag 15\% plots: (a) the PCC voltage without TSC, and (b) the PCC voltage with TSC. 


\section{The PCC voltage with sag $20 \%$ :}

When The PCC voltage is decreased to $79.75 \%$ of its normal value, for duration $400 \mathrm{~ms}$, from $\mathrm{t}=100 \mathrm{~ms}$ till $\mathrm{t}=500 \mathrm{~ms}$, as shown in figure $(6-\mathrm{a})$. The TSC mitigates the PCC voltage to $95.89 \%$ with $\mathrm{Q}=1.388 \mathrm{Mvar}$, as shown in figure (6-b).

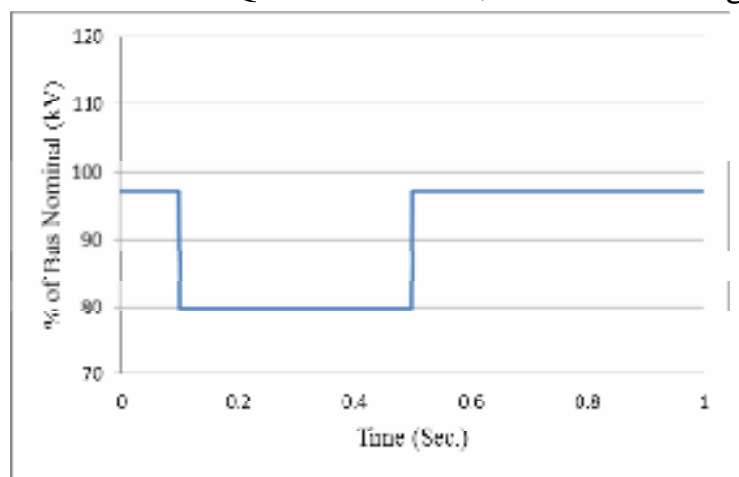

(a)

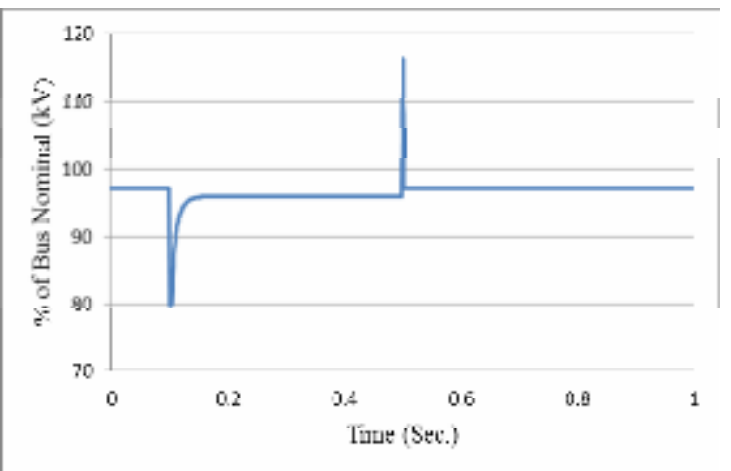

(b)

Figure 6: The PCC voltage with sag $20 \%$ plots: (a) the PCC voltage without TSC, and (b) the PCC voltage with TSC.

\section{The PCC voltage with sag $25 \%$ :}

When The PCC voltage is decreased to $75.50 \%$ of its normal value, for duration $400 \mathrm{~ms}$, from $\mathrm{t}=100 \mathrm{~ms}$ till $\mathrm{t}=500 \mathrm{~ms}$, as shown in figure $(7-\mathrm{a})$. The TSC mitigates the PCC voltage to $94.78 \%$ with $\mathrm{Q}=1.681 \mathrm{Mvar}$, as shown in figure (7-b).

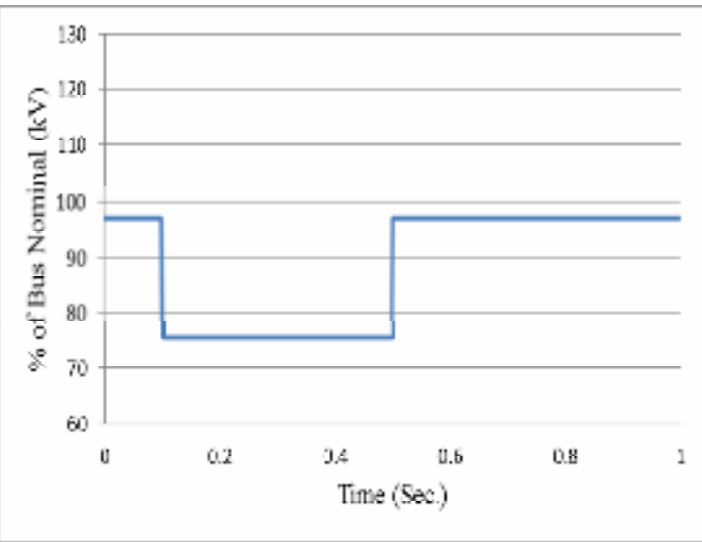

(a)

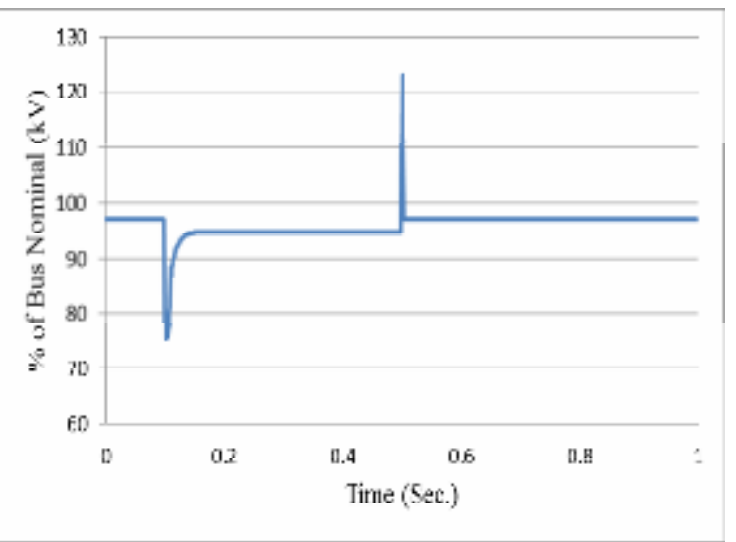

(b)

Figure 7: The PCC voltage with sag 25\% plots: (a) the PCC voltage without TSC, and (b) the PCC voltage with TSC.

\section{The PCC voltage with sag $30 \%$ :}

When The PCC voltage is decreased to $70.80 \%$ of its normal value, for duration $400 \mathrm{~ms}$, from $\mathrm{t}=100 \mathrm{~ms}$ till $\mathrm{t}=500 \mathrm{~ms}$, as shown in figure $(8-\mathrm{a})$. The TSC mitigates the PCC voltage to 93.26\% with $\mathrm{Q}=1.891 \mathrm{Mvar}$, as shown in figure (8-b). 
VOLTAGE SAG ENHANCEMENT IN MICROGRID WITH APPLICATIONS ON SENSITIVE LOADS

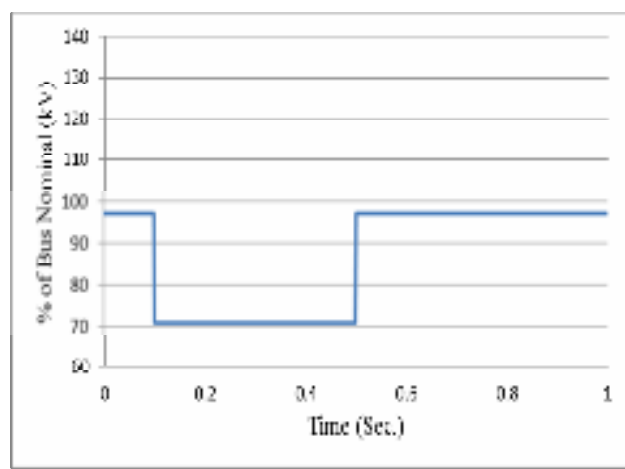

(a)

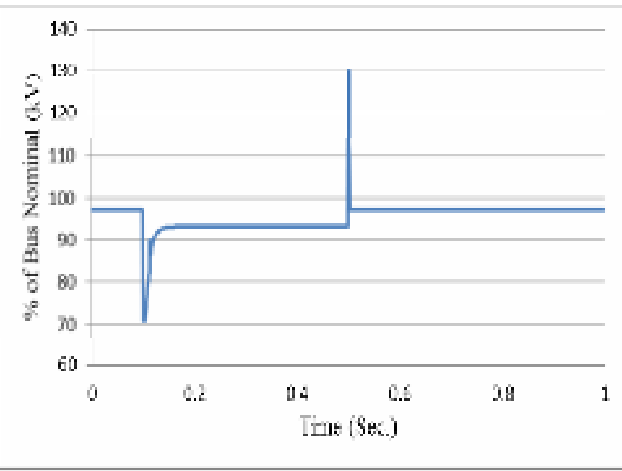

(b)

Figure 8: The PCC voltage with sag 30\% plots: (a) the PCC voltage without TSC, and (b) the PCC voltage with TSC.

\section{The PCC voltage with sag $35 \%$ :}

When The PCC voltage is decreased to $66.36 \%$ of its normal value, for duration $400 \mathrm{~ms}$, from $\mathrm{t}=100 \mathrm{~ms}$ till $\mathrm{t}=500 \mathrm{~ms}$, as shown in figure (9-a). The TSC mitigate the PCC voltage to $91.99 \%$ with $\mathrm{Q}=2.094$ Mvar, as shown in figure (9-b).

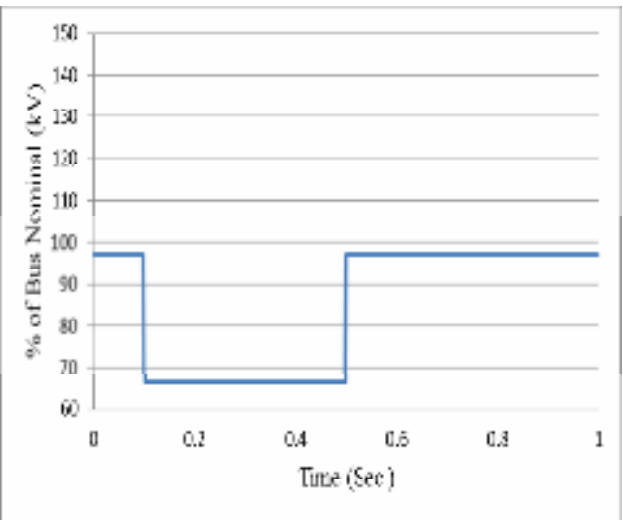

(a)

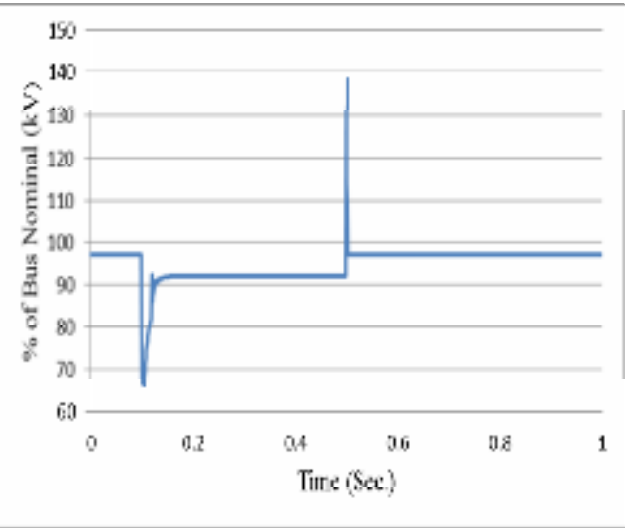

(b)

Figure 9: The PCC voltage with sag 35\% plots: (a) the PCC voltage without TSC, and (b) the PCC voltage with TSC.

Table 2 shows the comparison of the PCC voltage with and without TSC in different type of sag. It can be seen that TSC gave an optimum performance and have the ability to mitigation of voltage sag at PCC bus.

Table 2: The comparison of the PCC voltage without and with TSC

\begin{tabular}{|c|c|c|c|}
\hline $\begin{array}{c}\text { The PCC voltage } \\
\text { with sag }\end{array}$ & $\begin{array}{c}\text { The PCC voltage } \\
\text { without TSC }\end{array}$ & $\begin{array}{c}\text { The PCC voltage } \\
\text { With TSC }\end{array}$ & $\begin{array}{c}\text { The amount of } \\
\text { Reactive Power } \\
\text { (Mvar) }\end{array}$ \\
\hline $15 \%$ & $85.84 \%$ & $94.65 \%$ & 0.848 \\
\hline $20 \%$ & $79.75 \%$ & $95.89 \%$ & 1.388 \\
\hline $25 \%$ & $75.50 \%$ & $94.78 \%$ & 1.681 \\
\hline $30 \%$ & $70.80 \%$ & $93.26 \%$ & 1.891 \\
\hline $35 \%$ & $66.36 \%$ & $91.99 \%$ & 2.094 \\
\hline
\end{tabular}


Figure 10 shows the relation between the voltage sag and Reactive Power.

A) The proposed control,

B) The amount of Reactive Power with PCC voltage sag

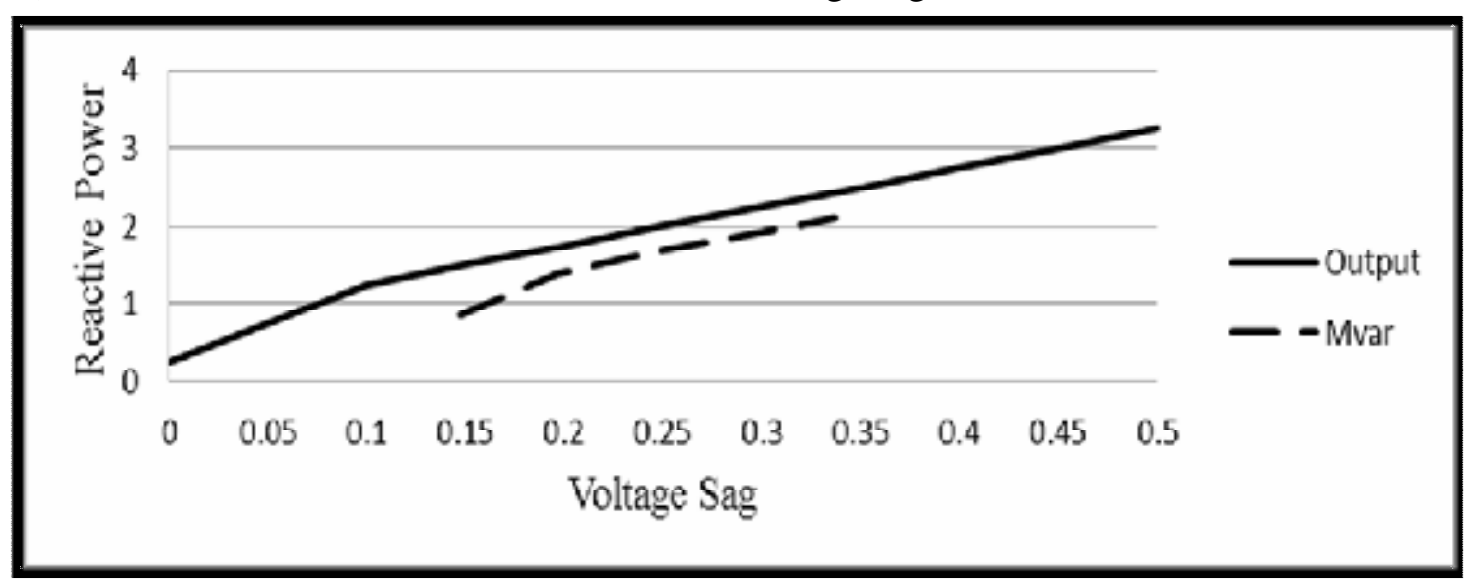

Figure 10: shows the relation between the voltage sag and Reactive Power

\section{CONCLUSION}

In this paper, we introduced the voltage sag as one of more occurring than any other power quality phenomena in the power distribution system. Thyristor switched capacitor banks are considered efficient and effective solution for voltage sag mitigation in the nuclear research reactor. Different types of voltage sag magnitude are modeled by using the user-defined dynamic modeling (UDM) tools in ETAP. The proposed control is effective to compensate the sensitive load voltage to the pre-fault value and makes it smooth under different cases of sags.

\section{REFERENCES}

[1] R. Zahira, P. Sheshathri, and M. S. Shafiullah, "Technical Investigation on Microgrid and Power Quality Impact", International Journal of Scientific \& Engineering Research, vol. 5, no. 4, pp. 183-187, 2014.

[2] IEEE Std 1100, "IEEE Recommended Practice for Powering and Grounding Electronic Equipment", 1999.

[3] J. Huang, and Z. Jiang, "Power Quality Assessment of Different Load Categories", Energy Procedia 141, pp. 345-351, 2017.

[4] S. D. Dhakulkar, V. A. Manwar, S. G. Banole, and B. S. Rakhonde, "Inspection Of Voltage Sags And Voltage Swells Incident In Power Quality Problems- A Review", International Research Journal of Engineering and Technology, vol. 4, no. 1, pp. 1734-1736, 2017.

[5] IEEE Std 1159, "IEEE Recommended Practice for Monitoring Electric Power Quality", 2009.

[6] A. Marroquin, A. Chee, and M. Manjarekar, "Implementation of a Switched Capacitor Control Scheme using User-Defined Dynamic Load Models", ETAP (Operation Technology, Inc), 2013.

[7] R. Varma, M. Mathur, and K. Rajiv, "Thyristor-Based Facts Controllers For Electrical Transmission Systems", A John Wiley and sons, 2002.

[8] S. Ghosh, and M. H. Ali. "Power Quality Enhancement by Coordinated Operation of Thyristor Switched Capacitor and Optimal Reclosing of Circuit Breakers", IET Generation, Transmission \& Distribution, Vol 9, no. 12, pp. 1301-1307, 2017. 
[9] A. D. Baing, and J. G. Jamnani, "Closed loop control of Thyristor Switched Capacitor (TSC) for instantaneous Reactive Power Compensation", International Journal of Engineering Development and Research, pp. 84-87, 2014.

[10] M. K. Khan, , and F. A. AbdulBasit. "Static VAR Compensator for Weak Grid Systems", International Journal of Engineering Works, Vol. 5, no. 1, pp. 10-15, 2018.

[11] G. F. Ledwich, S. H. Hosseini, and G. F. Shannon, "Voltage Balancing Using Switched Capacitors", Electric Power Systems Research, vol. 24, no. 2, pp. 85-90, 1992.

[12] R. B. Chavan, R. M. Gadade, and R. D. Magdum, "Transient Free TSC Compensator For Reactive Load with Closed Loop Control", International Journal of Emerging Technology and Innovative Engineering, vol. 2, no. 4, pp. 244-250, 2016.

[13] Z. Jianhua, D. Guangping, X. Gang, Z. Jie, Z. Hui, and W. Shuying, "Design of The Control System for Thyristor Switched Capacitor Devices", Transmission and Distribution Conference and Exposition, pp. 606-610, 2003.

[14] B. S. Patel, "Reactive Power Compensation In Transmission System with The Help of FACTS Device Thyristor Switch Capacitor (TSC)", International Journal of Engineering Technology Science and Research, Vol 4, no. 12, pp. 1214-1217, 2017.

[15] A. Mondzik, et al. , "High Efficiency Switched Capacitor Voltage Doubler with Planar CoreBased Resonant Choke." Compatibility, Power Electronics and Power Engineering (CPEPOWERENG), 2016 10th International Conference on. IEEE, 2016.

[16] L. He, et al., "Research on Asynchronous Starting Characteristics of Synchronous Motors Based on TSC Reactive Power Compensator." Current Trends in Computer Science and Mechanical Automation, Vol. 2, pp. 510-517, 2017.

[17] V. N. Ganesh, R. Banerjee, and B. Debgupta, "Improving power quality using thyristor controlled series capacitor." Advances in Natural and Applied Sciences, Vol 10, no. 14, pp. 264-269, 2016.

[18] S. Chirantan, et al., "Nodal Voltage Magnitude Control by Integrated Transformer FiringAngle Model Based TSC." Technologies for Smart-City Energy Security and Power (ICSESP), 2018. IEEE, 2018. 